\title{
Comparison of Constrained Acetabular Components and Dual Mobility Cups in Revision Total Hip Arthroplasty: A Literature Review
}

\author{
Eduard Van Eecke, MD, Jens Vanbiervliet, MD, Jan Dauwe, MD, MSc, Michiel Mulier, MD, PhD \\ Department of Orthopedic Surgery, University Hospitals Leuven, Leuven, Belgium
}

\begin{abstract}
Recurrent instability remains a common cause of failure after revision total hip arthroplasty (THA). Dual mobility (DM) cups and designs with constrained acetabular liners (CAL) have both been developed to help overcome this challenge. The aim of this report is to compare safety and efficacy outcomes of both designs based on the literature. A comprehensive literature review including published evidence on the results of DM and CAL in revision THA was performed and summarized. Available literature focusing on overall survival, dislocation, loosening, intra-prosthetic dislocation (IPD), and functional outcomes were analysed. Forty-six reports including an evaluation of 5,617 total hips were evaluated were included in the review. The included studies were divided into two distinct groups based on implantation approach: i) CAL $(n=15)$ and ii) DM $(n=31)$. The DM group had higher overall survival rates $(94.7 \%$ vs. $81.0 \%)$, lower dislocation rates (2.6\% vs. $11.0 \%)$, and lower acetabular loosening rates ( $1.0 \%$ vs. $2.0 \%$ ) compared to the CAL group. IPDs were reported in 6 studies (mean rate, $0.6 \%$ ). No differences in functional outcomes were identified due to incomplete reports. Our observations reveal that designs with CAL have poorer outcomes as compared to DM cups in revision THA. Currently, the use of DM seems more appropriate since they offer lower rates of dislocations, loosening and re-revisions in the short- and mid-term. Concerns regarding the potential of increased wear in a younger, high-demand population require additional data and evaluation by long-term studies for the DM design.
\end{abstract}

Key Words: Dual mobility, Total hip arthroplasty, Constrained, Dislocation, Revision

Submitted: July 6, 2019 1st revision: October 10, 2019

Final acceptance: October 23, 2019

Address reprint request to

Eduard Van Eecke, MD

(https://orcid.org/0000-0001-9749-3785)

Department of Orthopedic Surgery, University Hospitals Leuven,

Herestraat 49, 3000 Leuven, Belgium

TEL: +32-476819657

E-mail: eduard.van.eeckedahotmail.com

This is an Open Access article distributed under the terms of the Creative Commons Attribution Non-Commercial License (http://creativecommons. org/licenses/by-nc/4.0) which permits unrestricted non-commercial use, distribution, and reproduction in any medium, provided the original work is properly cited.

\section{INTRODUCTION}

Total hip arthroplasty (THA) is regarded as one of the most successful and cost-effective surgical procedures in end-stage hip arthritis ${ }^{1-3)}$. THA effectively reduces pain, improves function, mobility and quality of life $\mathrm{e}^{3)}$. As health care continues to improve and life expectancy increases, the demand for total joint arthroplasty will rise to reflect this more active, aging population ${ }^{2}$. Internationally, the amount of THAs is expected to increase by $170 \%$ between now and 2030. In addition, an increasing number of THA require revision; total hip revisions are also projected to increase by $137 \%$ by $2030^{2,4-7)}$. Complications after THA can be very challenging for both the surgeon and the 


\section{Hip \& Pelvis}

Hip Pelvis 32(2): 59-69, 2020

patient $t^{6}$. Thromboembolic disease, infection, peri-prosthetic fracture, aseptic loosening and dislocation are the most common postoperative complications.

Postoperative dislocation remains a persistent, disabling complication after THA. Recurrent instability after revision THA represents an even greater burden and is the leading indication for re-revision surgery ${ }^{8}$. Dislocation rates range between $0.3 \%$ and $10 \%$ in primary $\mathrm{THA}^{5,9}$. Depending on the reasons for revision, dislocation rates after revision THA varies from $5.0 \%$ to $30.0 \%{ }^{2,4,59-12}$. Contributing factors to instability include component malposition, impingement, inadequate soft tissue tension, abductor insufficiency, neuromuscular disorders, cognitive dysfunctions, and noncompliance. In many cases, the etiology is multifactorial ${ }^{1,699}$. Several prosthetic options and surgical approaches have been tested to both prevent and treat instability (e.g., component reorientation, trochanteric advancement, soft tissue reinforcement, capsulorraphy, large-diameter femoral heads, constrained liners, dual mobility constructs) ${ }^{3,12-15)}$, however, none are without risk ${ }^{9,16)}$.

The purpose of this study is to review literature comparing outcomes of constrained acetabular components with those of dual mobility (DM) cups in revision THA. In view of the increased importance of revision THAs, this study aims to compare the outcomes of both implants including overall survival, dislocation rates, implant migration/loosening, DM implant-specific complications (IPD), and functional outcomes (Harris hip score, HHS). Conversion to a DM design and a constrained liner are both procedures for recurrent instability. In current clinical practice, constrained liners are only used in a salvage procedure ${ }^{17,18}$; DM cups, on the other hand, are also used in primary THA.

The principle feature of constrained acetabular components is to hold the femoral head captive within the cup by means of a locking ring mechanism ${ }^{8,13,19,20)}$. There are two prevailing designs for constrained implants: the constrained tripolar and the locking ring ${ }^{5,13}$. In this study, constrained tripolar devices are not included. A constrained liner is a device consisting of a polyethylene (PE) liner and a reinforcing

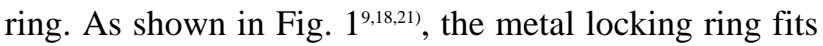
into a groove on the outer surface of the liner to reinforce the capture of the femoral head within the liner ${ }^{22}$. These constrained components are designed to physically resist dislocation by avoiding re-expansion of the liner. The metal locking ring allows immediate stability, but may be associated with a reduced range of motion (ROM) due to impingement of the neck on the PE liner ${ }^{8,22}$. The restricted movement of the components may increase the forces at the bone/implant interface, increasing the risk of aseptic loosening and the necessity for re-revision ${ }^{16}$. Implant failure can be classified to five distinct types: Type I failure is failure at the implant-bone interface. Type II and III failures are respectively disconnection of the PE liner from the cup or locking ring failure. Type IV failure is dislocation of the femoral head from the liner. Type $\mathrm{V}$ failure is infection (Table 1) 1,8,9,12,23-25).

DM cups ensure stability using a different biomechanical concept than the constrained locking ring mechanism. While the DM design has been utilized for more than 25 years in Europe, it only became available in North-America in 2009 when FDA approval was achieved ${ }^{1,2,26)}$. A DM cup is made up of two different articulations, one between the femoral head and the PE liner, and a second between the liner and the acetabular shell ${ }^{2}$. Thus, the first motion arises between the small femoral head and the inner/ concave surface of the PE liner, until the neck of the

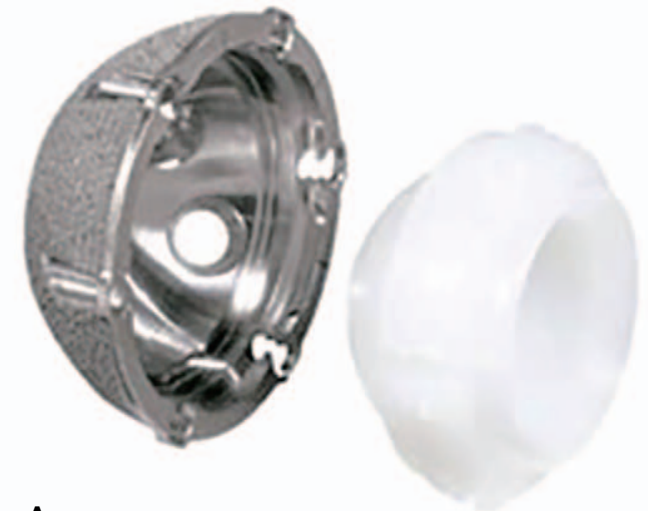

A

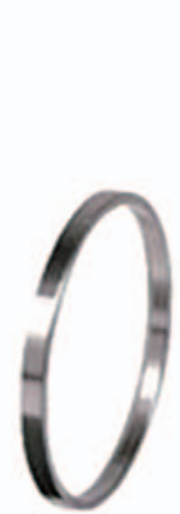

B

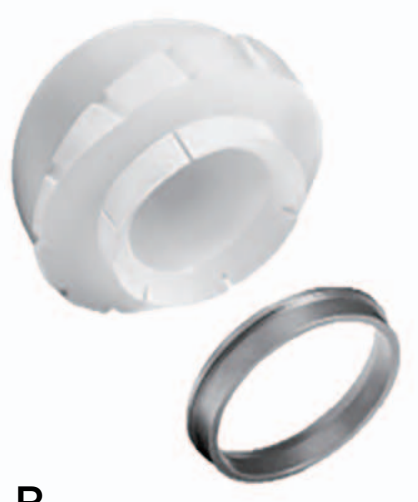

Fig. 1. Example of constrained acetabular liners with locking ring mechanism. (A) Duraloc constrained system (DePuy Synthes ${ }^{\mathbb{B}}$ ). (B) Trilogy Acetabular System Constrained Liner (Zimmer $\left.{ }^{\mathbb{B}}\right)^{9,18,211}$. 
Eduard Van Eecke et al. Comparison of Constrained Acetabular Components and DM Cups in Revision THA

Table 1. Implant Failure Classifications $\mathbf{s}^{8,9,12,23-25}$

\begin{tabular}{ll}
\hline \hline Type I & Failure at bone/cup interface (cementless) or bone/cement interface (cemented) \\
Type II & Liner/cup (cementless) or liner/cement (cemented) disengagement \\
Type III & Locking ring failure \\
Type IV & Dislocation of femoral head from PE Liner \\
Type V & Infection (deep/superficial) \\
\hline
\end{tabular}

PE: polyethylene.

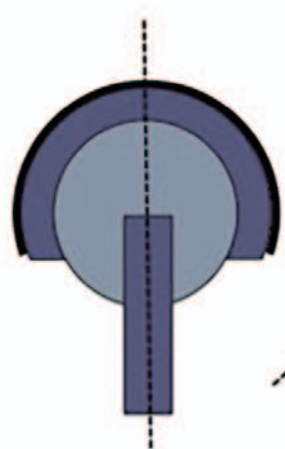

A

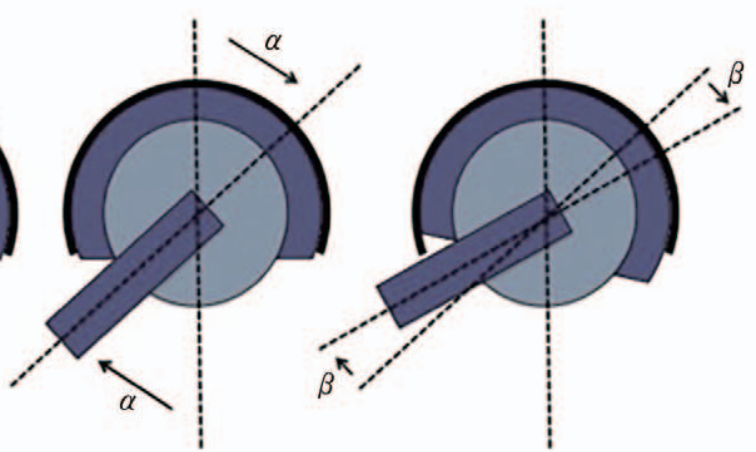

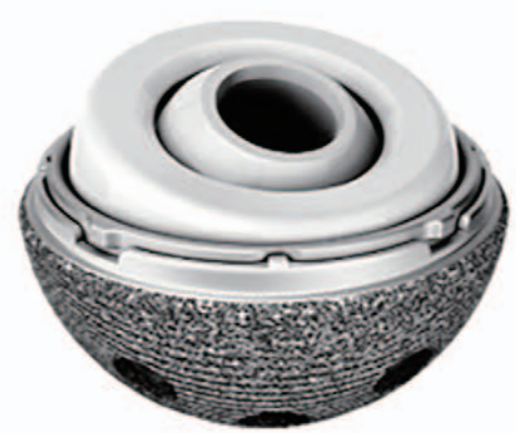

B

Fig. 2. (A) Articular motion of the dual mobility (DM) design. The femoral head rotates within the liner until contact is made $(\alpha)$, at which point the liner then rotates within acetabular shell ( $\beta$ ). (B) Example of DM cup (MDM Stryker) $)^{27}$.

femoral stem reaches the liner. As shown in Fig. $2^{27}$, the secondary motion occurs between the outer/convex surface of the PE liner and the acetabular metal cup, when a higher ROM is required ${ }^{1,28)}$. DM is therefore expected to improve the ROM to impingement ${ }^{29}$. The purpose of DM cups is to provide improved head-to-neck ratio, a larger effective head size and a higher jump distance, all of which lead to enhanced stability ${ }^{1,10,26,30,31}$. Major concerns with DM cups include accelerated PE wear due to an additional bearing surface, aseptic loosening and IPD ${ }^{1-3,29}$. IPD is a unique failure mechanism for DM constructs, in which the inner femoral head dislodges from the outer PE liner ${ }^{10,32}$. The metallic head can then articulate directly with the acetabular socket, causing devastating complications, including rapid wear and severe soft tissue metallosis, that will necessitate re-revision ${ }^{2,14,32}$. To prevent the mentioned concerns about accelerated wear on the additional bearing surface, cross-linked ultra-high molecular weight polyethylene (UHMWPE) doped with vitamin-E (an anti-oxidant) have been integrated into DM implants ${ }^{2,29,33)}$.

\section{MATERIALS AND METHODS}

PubMed/Medline, Embase, Cochrane Library and Trip
Database were searched for articles published up to May 2018. A search was conducted using various combinations of the following search terms: "total hip arthroplasty", "total hip replacement”, "revision hip arthroplasty”, "revision hip replacement", "constrained", "constrained liners", "constrained acetabular liners", "constrained components", "dual mobility", "dual-mobility", "bousquet”, "complications", “outcome”, "failure", "instability”, "dislocation”, "intra-prosthetic dislocation", "loosening”, "aseptic loosening”, "acetabular loosening". There were no set limitations on the year of publication ${ }^{1}$. Only English language papers were evaluated. No limitations were set concerning the category of study (retro-/prospective design), follow-up period or the number of patients enlisted. Inclusion criteria were articles investigating the outcomes of revision THA with constrained acetebular components or a DM design. Patients undergoing primary THA or revision with tripolar constrained devices (Omnifit Osteonics; Trident Stryker, Kalamazoo, MI, USA) were not included in the review. Duplicates, literature reviews, animal studies, in vitro investigations, cadaveric studies, technical notes and instructional courses were excluded. Additionally, reference lists of the included papers were manually inspected by the author for missed articles $^{1,32}$. A flow chart is enclosed according to the PRISMA 


\section{Hip \& Pelvis}

Hip Pelvis 32(2): 59-69, 2020

guidelines (Fig. 3).

A variety of outcomes were assessed. For each study, we collected data including the number of hips undergoing revision THA, the mean follow-up duration and the mean age of the study population. First, we assessed the overall survival rates. Survival rate or cup survivorship was defined as "1-surgical re-revision due to all causes". Second, we assessed the incidence rates of the most common complications in revision THA. The first complication evaluated in this study was dislocation rate. Thereafter, we assessed the rate of acetabular loosening, classically described as deterioration of bone implant interface with a measurable migration of the $\operatorname{cup}^{34,35)}$. Acetabular loosening is mostly evaluated radiographically according to the DeLee and Charnley classification (Fig. 4) ${ }^{23,36-40)}$.

Finally, the rate of IPD was analysed in all studies involving DM constructs.

Clinical evaluations were assessed using the HHS, a clinician-based outcome scale conducted by a well-qualified, professional health care provider ${ }^{41,42}$. This standardized outcome measure is a rating scale of 100 points with domains of pain, function, ROM and deformity. Higher scores

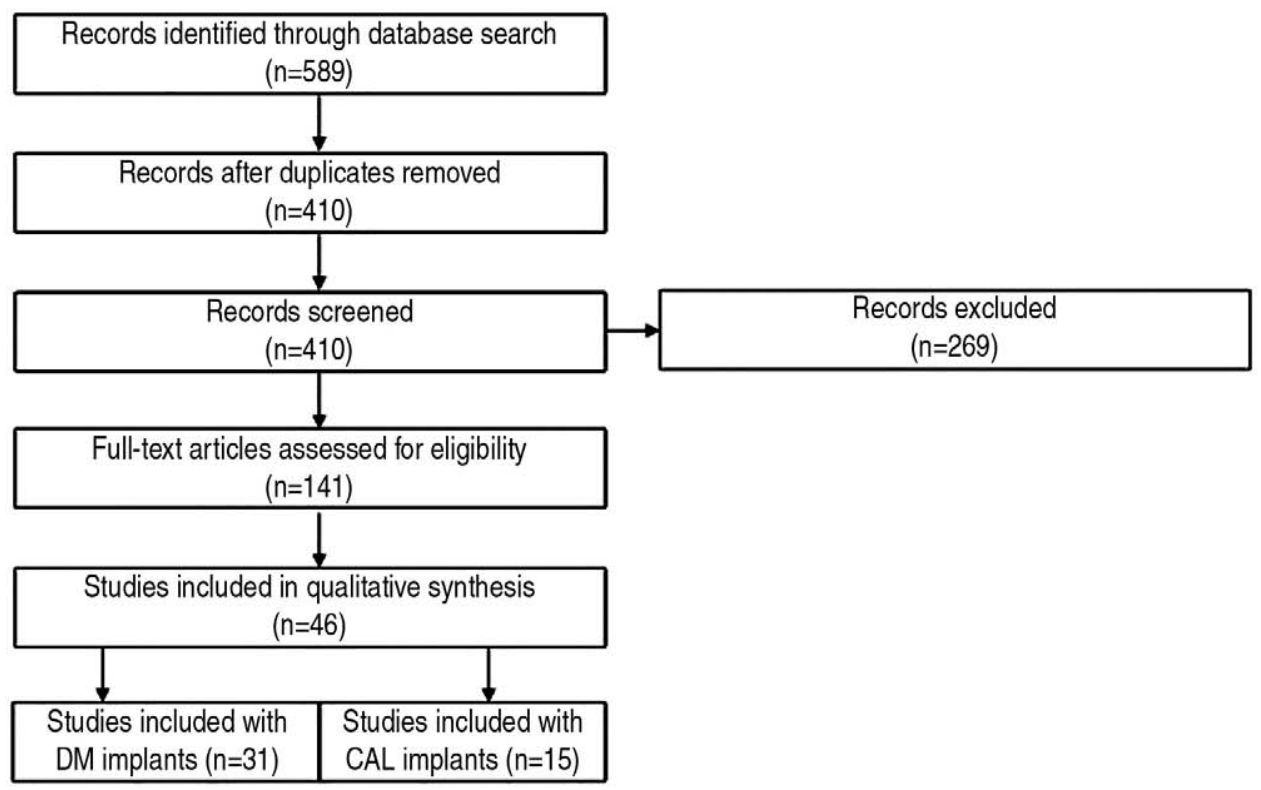

Fig. 3. Literature search/flow chart according to PRISMA guidelines.

DM: dual mobility, CAL: constrained acetabular liners.
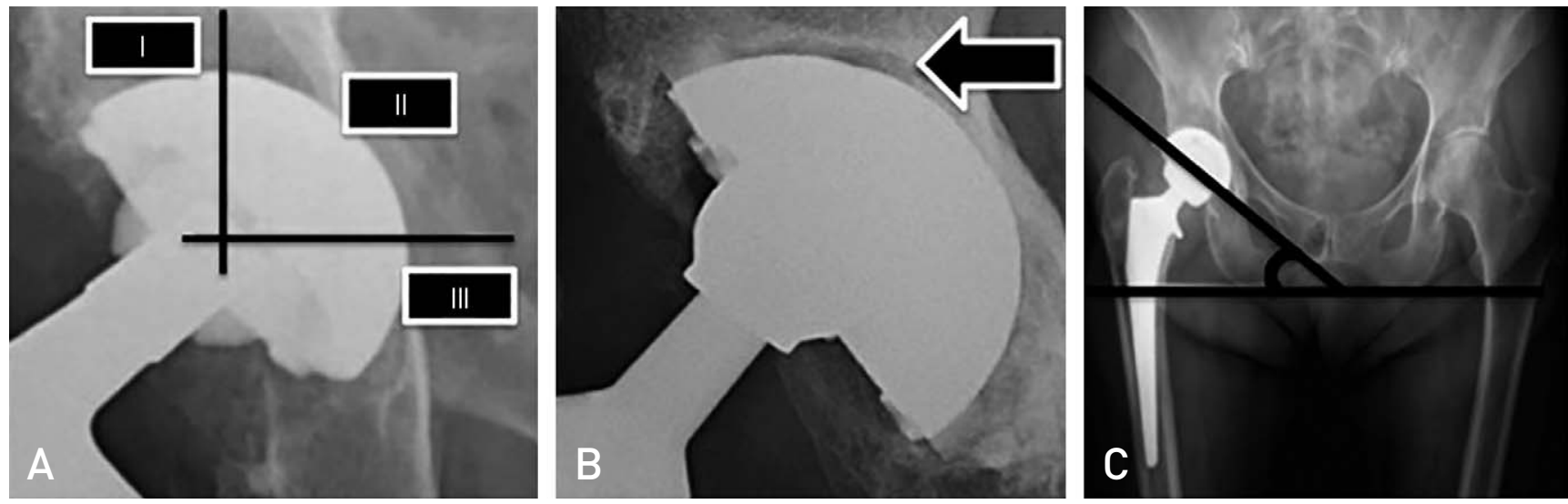

Fig. 4. (A) DeLee and Charnley acetabular zones. The acetabulum is divided into three equal zones. Acetabular components are considered loose if they have migrated $>3 \mathrm{~mm}$ in one zone, or if there is a circumferential peri-acetabular radiolucent line of at least $2 \mathrm{~mm}$ in all three zones ${ }^{23,37-40)}$. (B) Radiolucent zone around acetabular component in zone I and zone II. (C) Acetabular inclination, the angle between the transischial line and a line through the lateral and medial margins of the acetabular cup. 
Eduard Van Eecke et al. Comparison of Constrained Acetabular Components and DM Cups in Revision THA

represent better outcomes and less dysfunction ${ }^{41,42)}$.

\section{RESULTS}

The literature search resulted in a total of 46 references. We divided the studies that met the inclusion criteria into two distinct groups. The first group included 15 studies reporting use of constrained acetabular liners (CAL) components in revision THA. Of the 15 includes articles, 14 had a retrospective design. Studies were published starting from 1994, the latest in 2017. A total of 1,924 hips were analysed in this group. The mean follow-up period ranged from 19 months to 120 months. The average age at the time of the procedure was $69.0 \pm 7.0$ years. The mean dislocation rate was $11.0 \%$ (range, $0-29.0 \%$; standard deviation [SD], 8.7) and average survival rate was $81.0 \%$ (range, 54.7-97.2\%; SD, 10.9). Evaluating all cases of acetabular loosening revealed a mean rate of $2.0 \%$ (range, $0-8.3 \% ; \mathrm{SD}, 2.8$ ).

The second group included 31 studies dealing with DM devices in the setting of revision THA; of these, 23 were retrospective. Analysis of the 31 reports included 3,693 hips. The first reports included in this review were published in 2009, at the time when FDA approval for DM devices was obtained in the United States. The average follow-up time ranged from 16 to 87 months. Mean age at surgery of the overall study population was $68.8 \pm 6.2$ years. Dislocation rates vary from $0-10.4 \%$ with a mean dislocation rate of $2.6 \pm 2.5 \%$. Overall survival ranged between $88.9 \%$ and $100 \%$, with a mean rate of $94.7 \pm 3.5 \%$. Analysis of acetabular loosening revealed a rate of $1.0 \%$ (range, $0-6.4 \% ; \mathrm{SD}, 1.5$ ). Of the 31 studies, 6 report one or more cases of IPD (range, $0-4.0 \%$ ). The average rate of IPD was $0.6 \pm 1.2 \%$. These data reconfirm that this unique complication encountered with DM cups is extremely rare ra, $^{3,5232}$.

Table 2-4,9,-12,14,16,19,21-24,28,30-32,36,39,43-73) summarize the extracted data. The results of this study led to the development of some general considerations about both designs ${ }^{32}$.

\section{DISCUSSION}

As seen from the aforementioned results, our main finding was that DM cups seem preferable to constrained cups. This literature review revealed higher survival rates for the DM designs compared to the CAL designs ( $94.7 \%$ vs. $81.0 \%$ ). Overall dislocation rates and loosening

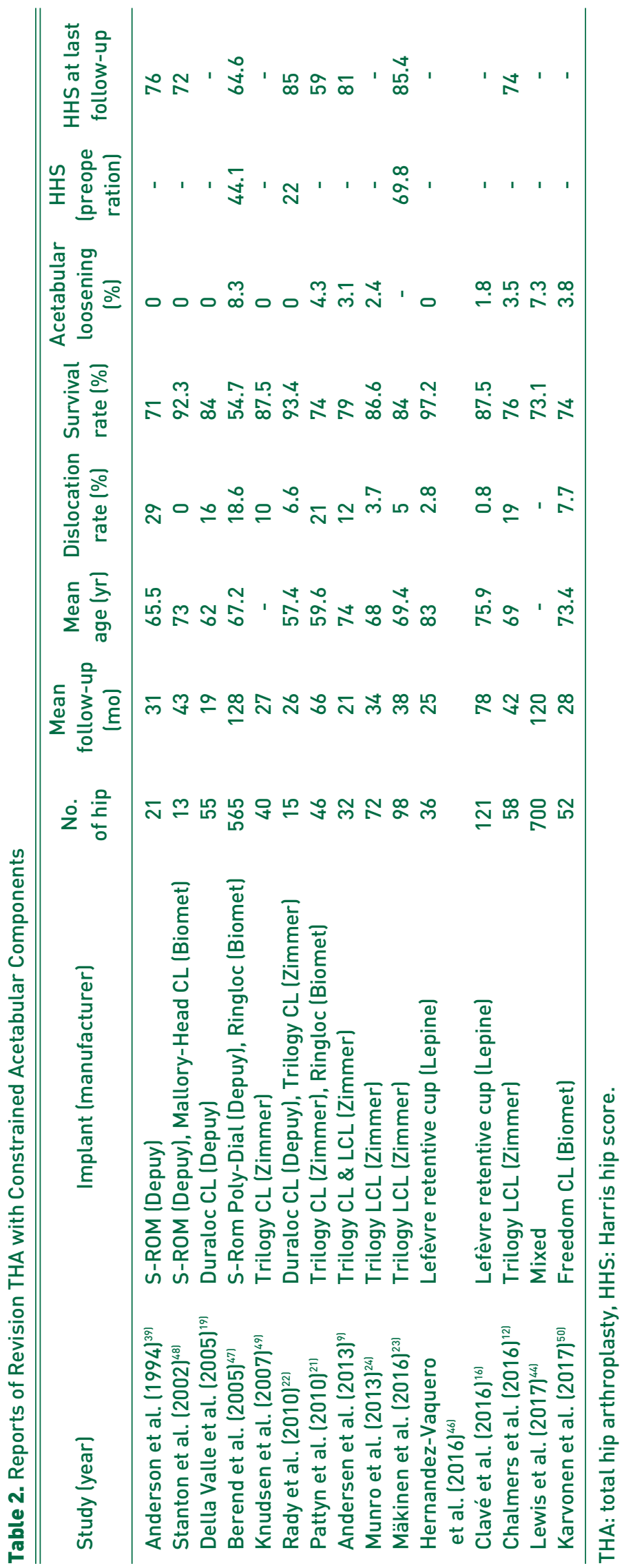




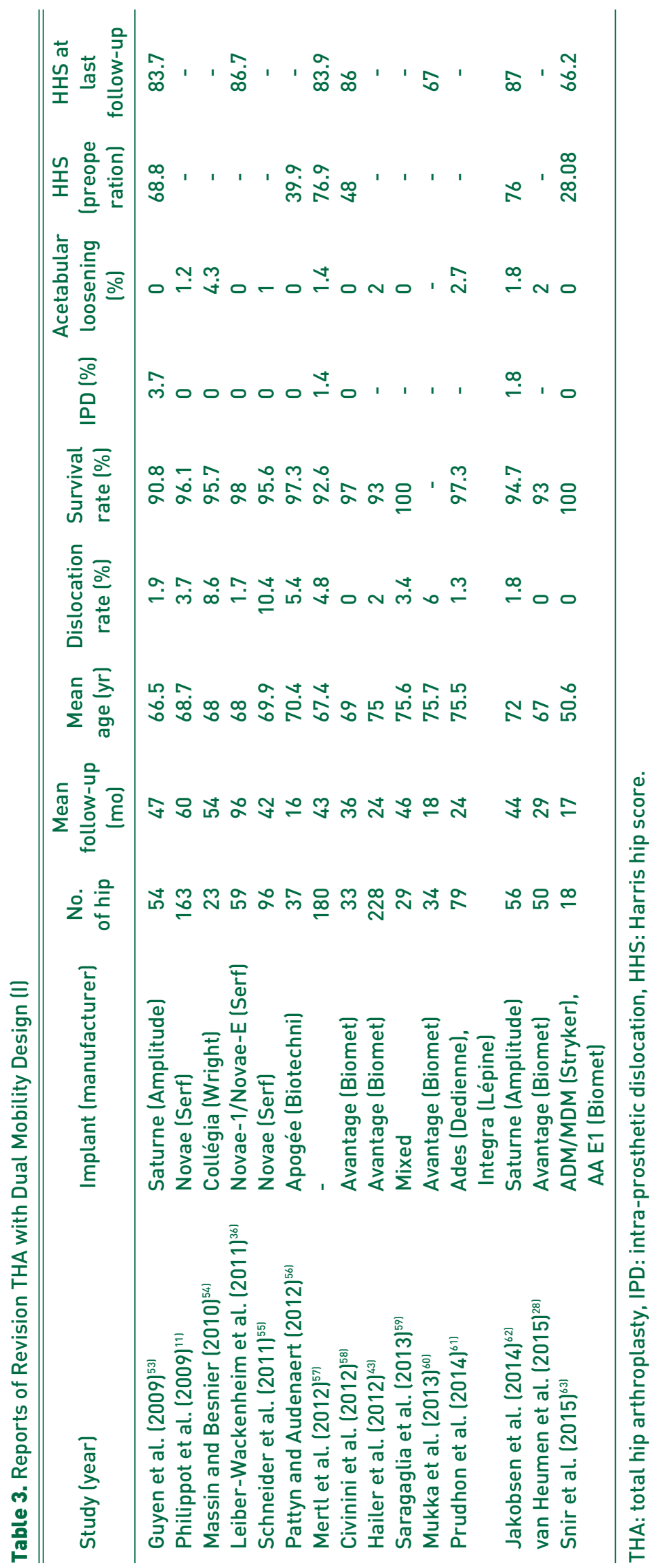

rates using DM in revision THA are lower than those reported in revision THA with a constrained implant ( $2.6 \%$ vs. $11.0 \%$ and $1.0 \%$ vs. $2.0 \%$, respectively). We emphasize that the success of these implants are reported with great variation. It is important to bear in mind that any type of prosthesis (including DM constructs or CAL constructs) cannot compensate for poor surgical technique or technical errors, such as incorrect implant orientation or inadequate restoration of soft-tissue tension ${ }^{5,17,26,29)}$. Surgeons must consider all the involved parameters including implant features, patient characteristics, positioning and soft tissues conditions. Risk factors for re-revision were described as younger age (50-59 yr) at the time of index surgery, revision for recurrent dislocation, revision following deep infection and the number of previous revision surgeries at the same joint ${ }^{11,43,51)}$. We report that most studies assess an elderly population (>65 yr), with few data on younger more active patients ${ }^{3}$. It is necessary to exercise caution when using DM or constrained implants in this high-demand population, in whom increased wear could be problematic ${ }^{2,3)}$.

Our results are in line with previous reviews. The general limitations of constrained designs are the decreased ROM to impingement, risk of breakage of the liner or retaining ring, increased component loosening due to high interfacial stress and excessive volumetric $\mathrm{PE}$ wear ${ }^{5,8,16,17,2,29,292)}$. Considering the high failure rates revealed in this review, we suggest that clinicians maintain the use of constrained liners limited to salvage scenarios in selected patients in whom other operative options are not practical or have not been successful ${ }^{5,8,17,18)}$. The most documented indications for use of a CAL design nowadays are senile, lowactivity patients, including those with neuromuscular disorders, cognitive impairment, idiopathic instability, abductor insufficiency, or insufficient soft tissue tension ${ }^{5,8,12,13,18,44-46)}$.

As mentioned above, DM devices provide a greater effective head size and improve the head-to-neck ratio of the implant ${ }^{10,38)}$. Therefore, DM is expected to increase the arc of motion of the hip joint contrary to constrained devices. However, the additional bearing surface in DM cups raises major concerns about accelerated wear and loosening as well as the newly encountered failure method IPD. Our findings demonstrate that IPD is exceedingly rare and the favorable low rates of loosening indicate 
Eduard Van Eecke et al. Comparison of Constrained Acetabular Components and DM Cups in Revision THA

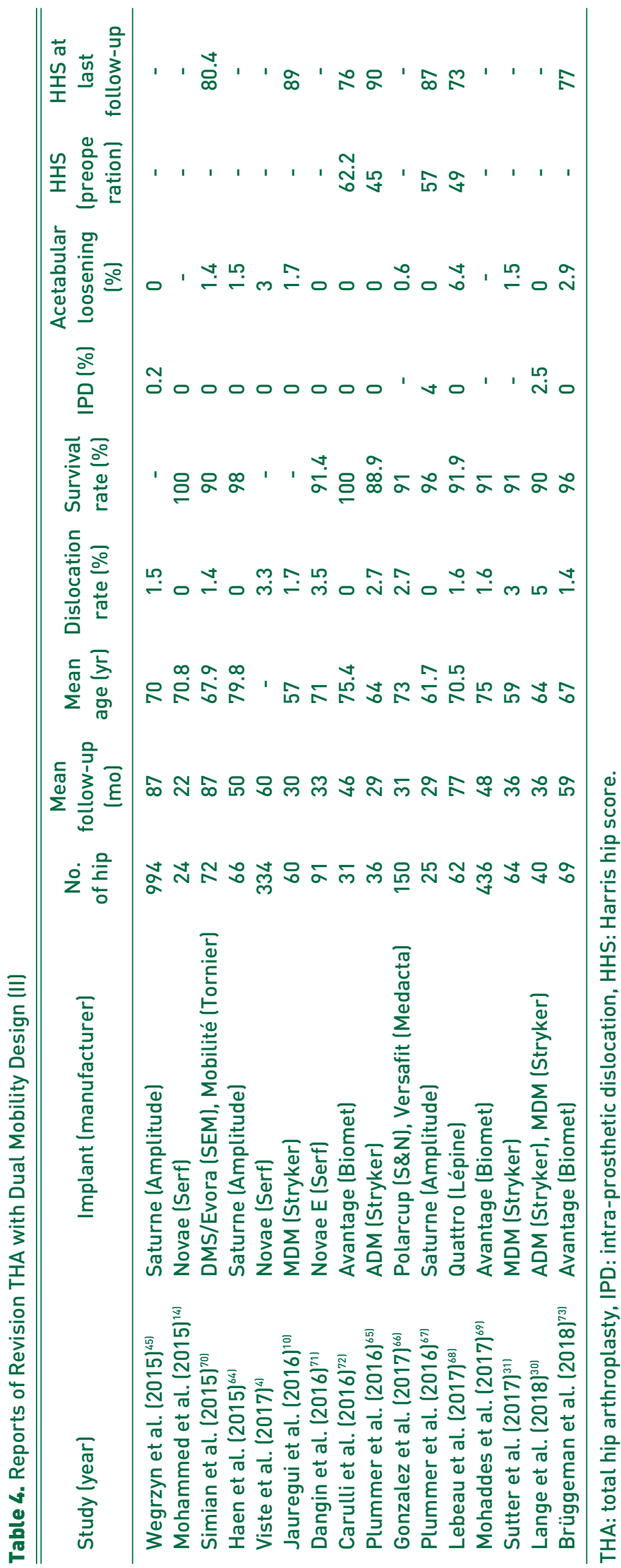

that DM cups do not result in high stresses at the boneimplant interface ${ }^{70)}$.

\section{DISLOCATION}

Our findings demonstrate great variation between the dislocation rate in DM and CAL designs. DM devices seem to lower the risk of dislocation in revision THA to $0.0-10.4 \%$ (mean, $2.6 \%$ ) compared to standard designs $(5.0-30.0 \%)^{2,4,5,9-12,74)}$. Constrained designs have been reported with moderate success revealing dislocation rates up to $29.0 \%$ (mean, $11.0 \%$ ). These results suggest that DM cups are effective in minimising the risk of dislocation after revision THA and are probably going to become the gold standard in treating THA dislocations $\mathrm{s}^{1,17,71,75)}$.

\section{FOLLOW-UP TIME}

Another issue to be considered is the fact that all but two studies involving the CAL design, have a short or medium follow-up time $(<10 \mathrm{yr})^{44,47}$. In the DM cup reports specifically, there are limited medium-term and no longer-term studies, likely because DM was unavailable in the United States until FDA approval in 2009. Since DM implants are utilized with increasing frequency in North America, further and longer-term follow-up will be needed to confirm the medium-term results.

\section{INFECTION}

Surprisingly, few studies evaluate postoperative infectious complications (e.g., superficial soft tissue colonization, deep peri-implant infection). Currently there is no scientific evidence suggesting that one of the discussed designs leads to significantly higher infection rates.

\section{SURGICAL APPROACH}

An additional factor that may influence the outcome of revision THA, in particular the dislocation rate, is the surgical approach. Multiple reports demonstrated that the posterior approach to the hip joint, requiring detachment of the posterior capsule and short external rotators, is correlated with an increased dislocation rate compared to the anterior, anterolateral, and lateral 
approaches ${ }^{6,76-78)}$. We were unable to draw significant conclusions here due to incomplete reports and substantial differences in indications for revision THA in the included studies.

\section{FUNCTIONAL OUTCOMES}

Another finding of this study is the lack of functional results in accordance with a clinical scale ${ }^{28}$. Few reports $(<50 \%)$ include clinician- and/or patient-reported functional outcomes in their results. The HHS is most commonly used, however, many studies report incomplete functional results without comparative preoperative scores. Scores established only at clinical follow-up but not at baseline are insufficient to allow for conclusions related to the potential impact of the treatment on quality of life ${ }^{73)}$. In a limited number of French studies, the Postel-Merle d'Aubigné score was used. Additionally, few patient-reported outcome measures are described (e.g., Oxford hip score, WOMAC score). We therefore suggest using universal clinical measurement instruments (clinician- and patient-reported) with comparative preoperative and follow-up postoperative results to provide information about the functional performance of the two implants ${ }^{28)}$.

\section{LIMITATIONS}

This review has several limitations ${ }^{1,70,72)}$. The main limitation is the inconsistent quality of the included studies. First, most papers included in this review have a retrospective design. Second, the majority of the studies are not randomized and lack a control group. Thirdly, many included reports have a small cohort size with an often heterogeneous patient population ${ }^{70)}$. Indications for revision THA are not taken into account individually and there is great variability among the patient population regarding demographics and diagnosis. Furthermore, various modifications and improvements have been made over the years to the mechanics, metallurgy and materials of the original DM or CAL designs ${ }^{2}$. Subsequent generations of the DM constructs with highly cross-linked UHMWPE and vitamin-E impregnated PE, dual hydroxyapatite and titanium coating instead of alumina, modular shells for screw fixation, cemented designs have all been introduced to improve cup fixation and decrease complications such as PE wear, dislocation, IPD and psoas irritation ${ }^{2,3,26)}$. For this reason it may be recommended to assess and compare the outcomes of different DM and CAL implant designs mutually in the future. No meta-analysis was performed. Finally, we should mention selection bias as a weakness of the present study as specific data was selectively extracted from the articles ${ }^{1}$. These limitations confine the level of evidence of this paper.

\section{CONCLUSION}

In conclusion, this comparative literature review revealed that designs with constrained acetabular components have poorer outcomes as compared to DM cups in revision THA. The use of DM seems more appropriate at the current time since they impose lower rates of dislocations, loosening and re-revisions in the short- and mid-term. While IPD is a new failure mechanism related to DM designs, it is extremely uncommon ${ }^{26,71}$. Additional data will be needed to assess long-term survivorship of DM cups and concerns regarding increased wear in a younger, high-demand patient population. Constrained designs are still an alternative option but only as salvage procedure for selected, lowdemand patients in case of failure of previous treatments ${ }^{12}$.

\section{CONFLICT OF INTEREST}

The authors declare that there is no potential conflict of interest relevant to this article.

\section{REFERENCES}

1. De Martino I, D’Apolito R, Soranoglou VG, Poultsides LA, Sculco PK, Sculco TP. Dislocation following total hip arthroplasty using dual mobility acetabular components: a systematic review. Bone Joint J. 2017;99(ASuppl1):18-24.

2.Plummer DR, Haughom BD, Della Valle CJ. Dual mobility in total hip arthroplasty. Orthop Clin North Am. 2014;45: 1-8.

3. De Martino I, Triantafyllopoulos GK, Sculco PK, Sculco TP. Dual mobility cups in total hip arthroplasty. World J Orthop. 2014;5:180-7.

4. Viste A, Desmarchelier R, Fessy MH. Dual mobility cups in revision total hip arthroplasty. Int Orthop. 2017;41:535-42.

5. Abdel MP, Padgett DE. Constrained liners in revision total hip replacement. Bone Joint J. 2013;95 Suppl A. doi: 10.1302/ 0301-620X/95B.33361.

6. Dargel J, Oppermann J, Brüggemann GP, Eysel P. Dislocation following total hip replacement. Dtsch Arztebl Int. 2014; 111:884-90.

7. Wera GD, Ting NT, Moric M, Paprosky WG, Sporer SM, Della Valle CJ. Classification and management of the unstable total hip arthroplasty. J Arthroplasty. 2012;27: 710-5.

8. Jones SA. Constrained acetabular liners. J Arthroplasty. 2018;33:1331-6. 
Eduard Van Eecke et al. Comparison of Constrained Acetabular Components and DM Cups in Revision THA

9. Andersen AV, Kjersgaard AG, Solgaard S. Trilogy-constrained acetabular component for recurrent dislocation. ISRN Orthop. 2013;2013:629201.

10. Jauregui JJ, Pierce TP, Elmallah RK, Cherian JJ, Delanois RE, Mont MA. Dual mobility cups: an effective prosthesis in revision total hip arthroplasties for preventing dislocations. Hip Int. 2016;26:57-61.

11. Philippot R, Adam P, Reckhaus M, et al. Prevention of dislocation in total hip revision surgery using a dual mobility design. Orthop Traumatol Surg Res. 2009;95:407-13.

12. Chalmers BP, Arsoy D, Sierra RJ, Lewallen DG, Trousdale RT. High failure rate of modular exchange with a specific design of a constrained liner in high-risk patients undergoing revision total hip arthroplasty. J Arthroplasty. 2016;31: 1963-9.

13. Su EP, Pellicci PM. The role of constrained liners in total hip arthroplasty. Clin Orthop Relat Res. 2004;(420):122-9.

14. Mohammed R, Hayward K, Mulay S, Bindi F, Wallace M. Outcomes of dual-mobility acetabular cup for instability in primary and revision total hip arthroplasty. J Orthop Traumatol. 2015;16:9-13.

15. Batailler C, Fary C, Verdier R, Aslanian T, Caton J, Lustig $\mathrm{S}$. The evolution of outcomes and indications for the dualmobility cup: a systematic review. Int Orthop. 2017;41: 645-59.

16. Clavé A, Maurer D, Tristan L, Dubrana F, Lefèvre C, Pandit H. Midterm survivorship of the Lefèvre constrained liner: a consecutive multisurgeon series of 166 cases. J Arthroplasty. 2016;31:1970-8.

17.Zagra L, Caboni E. Total hip arthroplasty instability treatment without dual mobility cups: brief overview and experience of other options. Int Orthop. 2017;41:661-8.

18. Williams JT Jr, Ragland PS, Clarke S. Constrained components for the unstable hip following total hip arthroplasty: a literature review. Int Orthop. 2007;31:273-7.

19. Della Valle CJ, Chang D, Sporer S, Berger RA, Rosenberg AG, Paprosky WG. High failure rate of a constrained acetabular liner in revision total hip arthroplasty. J Arthroplasty. 2005; 20(7 Suppl 3):103-7.

20. Khan RJ, Fick D, Alakeson R, Li MG, Nivbrant B, Wood $\mathrm{D}$. The constrained acetabular component for hip instability. J Arthroplasty. 2007;22:377-82.

21. Pattyn C, De Haan R, Kloeck A, Van Maele G, De Smet $\mathrm{K}$. Complications encountered with the use of constrained acetabular prostheses in total hip arthroplasty. J Arthroplasty. 2010;25:287-94.

22. Rady AE, Asal MK, Bassiony AA. The use of a constrained cementless acetabular component for instability in total hip replacement. Hip Int. 2010;20:434-9.

23. Mäkinen TJ, Fichman SG, Rahman WA, et al. The focally constrained liner is a reasonable option for revision of unstable total hip arthroplasty. Int Orthop. 2016;40:2239-45.

24. Munro JT, Vioreanu MH, Masri BA, Duncan CP. Acetabular liner with focal constraint to prevent dislocation after THA. Clin Orthop Relat Res. 2013;471:3883-90.

25. Guyen O, Lewallen DG, Cabanela ME. Modes of failure of Osteonics constrained tripolar implants: a retrospective analysis of forty-three failed implants. J Bone Joint Surg Am. 2008;90:1553-60.
26. Abdel MP. Dual-mobility constructs in revision total hip arthroplasties. J Arthroplasty. 2018;33:1328-30.

27. Moore C, Orlandini L. The dual mobility concept in total hip arthroplasty. Bone Joint Sci. 2012;3:1-8.

28. van Heumen M, Heesterbeek PJ, Swierstra BA, Van Hellemondt GG, Goosen JH. Dual mobility acetabular component in revision total hip arthroplasty for persistent dislocation: no dislocations in 50 hips after 1-5 years. J Orthop Traumatol. 2015; 16:15-20.

29. Guyen O. Constrained liners, dual mobility or large diameter heads to avoid dislocation in THA. EFORT Open Rev. 2017; 1:197-204.

30. Lange JK, Spiro SK, Westrich GH. Utilizing dual mobility components for first-time revision total hip arthroplasty for instability. J Arthroplasty. 2018;33:505-9.

31. Sutter EG, McClellan TR, Attarian DE, Bolognesi MP, Lachiewicz PF, Wellman SS. Outcomes of modular dual mobility acetabular components in revision total hip arthroplasty. J Arthroplasty. 2017;32:S220-4.

32. De Martino I, D’Apolito R, Waddell BS, McLawhorn AS, Sculco PK, Sculco TP. Early intraprosthetic dislocation in dual-mobility implants: a systematic review. Arthroplast Today. 2017;3:197-202.

33. Oral E, Christensen SD, Malhi AS, Wannomae KK, Muratoglu OK. Wear resistance and mechanical properties of highly cross-linked, ultrahigh-molecular weight polyethylene doped with vitamin E. J Arthroplasty. 2006;21:580-91.

34. Rastogi S, Trikha V, Bhan S, Bal C. Aseptic loosening of the acetabular component in relation to the positioning of prosthesis. Indian J Orthop. 2002;36:3.

35. Picado CHF, Garcia FL, Kanabushi C, Carvalho S. Pain as symptom of threaded acetabular cup loosening. Acta Ortop Bras. 2005; 13:2004-6.

36. Leiber-Wackenheim F, Brunschweiler B, Ehlinger M, Gabrion A, Mertl P. Treatment of recurrent THR dislocation using of a cementless dual-mobility cup: a 59 cases series with a mean 8 years' follow-up. Orthop Traumatol Surg Res. 2011;97:8-13.

37. Williams J, Neep M. Radiographic evaluation of hip replacements. Spectrum. 2012;19:8-12. Available from: https://www.minnisjournals.com.au/articles/rad\%20hip $\% 2$ Oassess\%20spec\%20sept\%2012.pdf.

38. Chalmers BP, Ledford CK, Taunton MJ, Sierra RJ, Lewallen DG, Trousdale RT. Cementation of a dual mobility construct in recurrently dislocating and high risk patients undergoing revision total arthroplasty. J Arthroplasty. 2018;33:1501-6.

39. Anderson MJ, Murray WR, Skinner HB. Constrained acetabular components. J Arthroplasty. 1994;9:17-23.

40. Watt I, Boldrik S, Langelaan EV, Smithuis R. Hip-arthroplasty [Internet]. The Radiology Assistant; 2006 [cited 2018 Nov 24]. Available from: http://www.radiologyassistant.nl/en/ p431c8258e7ac3/hip-arthroplasty.html.

41. Nilsdotter A, Bremander A. Measures of hip function and symptoms: Harris Hip Score (HHS), Hip Disability and Osteoarthritis Outcome Score (HOOS), Oxford Hip Score (OHS), Lequesne Index of Severity for Osteoarthritis of the Hip (LISOH), and American Academy of Orthopedic Surgeons (AAOS) hip and knee questionnaire. Arthritis Care Res (Hoboken). 2011;63 Suppl 11:S200-7. 
42. Harris WH. Traumatic arthritis of the hip after dislocation and acetabular fractures: treatment by mold arthroplasty. An end-result study using a new method of result evaluation. J Bone Joint Surg Am. 1969;51:737-55.

43. Hailer NP, Weiss RJ, Stark A, Kärrholm J. Dual-mobility cups for revision due to instability are associated with a low rate of re-revisions due to dislocation: 228 patients from the Swedish Hip Arthroplasty Register. Acta Orthop. 2012; 83:566-71.

44. Lewis PL, Graves SE, de Steiger RN, Cuthbert AR. Constrained acetabular components used in revision total hip arthroplasty: a registry analysis. J Arthroplasty. 2017;32:3102-7.

45. Wegrzyn J, Tebaa E, Jacquel A, Carret JP, Béjui-Hugues J, Pibarot V. Can dual mobility cups prevent dislocation in all situations after revision total hip arthroplasty? J Arthroplasty. 2015;30:631-40.

46. Hernandez-Vaquero D, Llorens De Los Rios J, Perez-Coto I, Iglesias-Fernandez S, Fernandez-Lombardia J, Cuervo-Olay MDC. Constrained acetabular liners in hip revision surgery. A low-cost solution for senile patients. Acta Orthop Belg. 2016;82:563-9.

47. Berend KR, Lombardi AV Jr, Mallory TH, Adams JB, Russell $\mathrm{JH}$, Groseth KL. The long-term outcome of 755 consecutive constrained acetabular components in total hip arthroplasty examining the successes and failures. J Arthroplasty. 2005; 20(7 Suppl 3):93-102.

48. Stanton DA, Bruce WJ, Goldberg JA, Walsh W. Salvaging unstable or recurrent dislocating total hip arthroplasty with the constrained acetabular component. J Orthop Surg (Hong Kong). 2002;10:165-9.

49. Knudsen R, Ovesen O, Kjaersgaard-Andersen P, Overgaard S. Constrained liners for recurrent dislocations in total hip arthroplasty. Hip Int. 2007;17:78-81.

50. Karvonen M, Karvonen H, Seppänen M, Liukas A, Koivisto M, Mäkelä KT. Freedom constrained liner for the treatment and prevention of dislocation in total hip arthroplasty. Scand J Surg. 2017;106:165-72.

51. Jo S, Jimenez Almonte JH, Sierra RJ. The cumulative risk of re-dislocation after revision THA performed for instability increases close to $35 \%$ at 15 years. J Arthroplasty. 2015; 30:1177-82.

52. Fricka KB, Marshall A, Paprosky WG. Constrained liners in revision total hip arthroplasty: an overuse syndrome: in the affirmative. J Arthroplasty. 2006;21(4 Suppl 1):121-5.

53. Guyen O, Pibarot V, Vaz G, Chevillotte C, Béjui-Hugues J. Use of a dual mobility socket to manage total hip arthroplasty instability. Clin Orthop Relat Res. 2009;467:465-72.

54. Massin P, Besnier L. Acetabular revision using a press-fit dual mobility cup. Orthop Traumatol Surg Res. 2010;96:913.

55. Schneider L, Philippot R, Boyer B, Farizon F. Revision total hip arthroplasty using a reconstruction cage device and a cemented dual mobility cup. Orthop Traumatol Surg Res. 2011;97:807-13.

56. Pattyn C, Audenaert E. Early complications after revision total hip arthroplasty with cemented dual-mobility socket and reinforcement ring. Acta Orthop Belg. 2012;78:357-61.

57. Mertl P, Combes A, Leiber-Wackenheim F, Fessy MH, Girard J, Migaud H. Recurrence of dislocation following total hip arthroplasty revision using dual mobility cups was rare in 180 hips followed over 7 years. HSS J. 2012;8:251-6.

58. Civinini R, Carulli C, Matassi F, Nistri L, Innocenti M. A dual-mobility cup reduces risk of dislocation in isolated acetabular revisions. Clin Orthop Relat Res. 2012;470: 3542-8.

59. Saragaglia D, Ruatti S, Refaie R. Relevance of a press-fit dual mobility cup to deal with recurrent dislocation of conventional total hip arthroplasty: a 29-case series. Eur J Orthop Surg Traumatol. 2013;23:431-6.

60. Mukka SS, Mahmood SS, Sjödén GO, Sayed-Noor AS. Dual mobility cups for preventing early hip arthroplasty dislocation in patients at risk: experience in a county hospital. Orthop Rev (Pavia). 2013;5:48-51.

61. Prudhon JL, Steffann F, Ferreira A, Verdier R, Aslanian T, Caton J. Cementless dual-mobility cup in total hip arthroplasty revision. Int Orthop. 2014;38:2463-8.

62. Jakobsen T, Kappel A, Hansen F, Krarup N. The dislocating hip replacement-revision with a dual mobility cup in 56 consecutive patients. Open Orthop J. 2014;8:268-71.

63. Snir N, Park BK, Garofolo G, Marwin SE. Revision of failed hip resurfacing and large metal-on-metal total hip arthroplasty using dual-mobility components. Orthopedics. 2015;38:369-74.

64. Haen TX, Lonjon G, Vandenbussche E. Can cemented dualmobility cups be used without a reinforcement device in cases of mild acetabular bone stock alteration in total hip arthroplasty? Orthop Traumatol Surg Res. 2015;101:923-7.

65. Plummer DR, Christy JM, Sporer SM, Paprosky WG, Della Valle CJ. Dual-mobility articulations for patients at high risk for dislocation. J Arthroplasty. 2016;31(9 Suppl):131-5.

66. Gonzalez AI, Bartolone P, Lubbeke A, et al. Comparison of dual-mobility cup and unipolar cup for prevention of dislocation after revision total hip arthroplasty. Acta Orthop. 2017;88:18-23.

67. Plummer DR, Botero HG, Berend KR, Pritchett JW, Lombardi AV, Della Valle CJ. Salvage of monoblock metal-on-metal acetabular components using a dual-mobility bearing. $J$ Arthroplasty. 2016;31:846-9.

68. Lebeau N, Bayle M, Belhaouane R, et al. Total hip arthroplasty revision by dual-mobility acetabular cup cemented in a metal reinforcement: a 62 case series at a minimum 5 years' follow-up. Orthop Traumatol Surg Res. 2017;103:679-84.

69. Mohaddes M, Cnudde P, Rolfson O, Wall A, Kärrholm J. Use of dual-mobility cup in revision hip arthroplasty reduces the risk for further dislocation: analysis of seven hundred and ninety one first-time revisions performed due to dislocation, reported to the Swedish Hip Arthroplasty Register. Int Orthop. 2017;41:583-8.

70. Simian E, Chatellard R, Druon J, Berhouet J, Rosset P. Dual mobility cup in revision total hip arthroplasty: dislocation rate and survival after 5 years. Orthop Traumatol Surg Res. 2015;101:577-81.

71. Dangin A, Boulat S, Farizon F, Philippot R. Prevention of dislocation risk during hip revision surgery with the dual mobility concept; study of a new generation of dual mobility cups. Surg Technol Int. 2016;29:314-9.

72. Carulli C, Macera A, Matassi F, Civinini R, Innocenti M. The use of a dual mobility cup in the management of recurrent 


\section{Hip \& Pelvis}

Eduard Van Eecke et al. Comparison of Constrained Acetabular Components and DM Cups in Revision THA

dislocations of hip hemiarthroplasty. J Orthop Traumatol. 2016;17:131-6.

73. Brüggemann A, Mallmin H, Hailer NP. Do dual-mobility cups cemented into porous tantalum shells reduce the risk of dislocation after revision surgery? Acta Orthop. 2018;89: 156-62.

74. Noble PC, Durrani SK, Usrey MM, Mathis KB, Bardakos NV. Constrained cups appear incapable of meeting the demands of revision THA. Clin Orthop Relat Res. 2012; 470:1907-16.

75. Wirth T, Stratmann L, Hinrichs F. Evolution of late presenting developmental dysplasia of the hip and associated surgical procedures after 14 years of neonatal ultrasound screening. J Bone Joint Surg Br. 2004;86:585-9.
76. Rosenlund S, Broeng L, Jensen C, Holsgaard-Larsen A, Overgaard $\mathrm{S}$. The effect of posterior and lateral approach on patient-reported outcome measures and physical function in patients with osteoarthritis, undergoing total hip replacement: a randomised controlled trial protocol. BMC Musculoskelet Disord. 2014;15:354.

77. Berry DJ, von Knoch M, Schleck CD, Harmsen WS. Effect of femoral head diameter and operative approach on risk of dislocation after primary total hip arthroplasty. J Bone Joint Surg Am. 2005;87:2456-63.

78. Berend KR, Sporer SM, Sierra RJ, Glassman AH, Morris MJ. Achieving stability and lower-limb length in total hip arthroplasty. J Bone Joint Surg Am. 2010;92:2737-52. 